\title{
Analysis of market concentration in creative industry
}

\author{
Mária Kozáková1,*, and Mária Kmety Barteková ${ }^{1}$ \\ ${ }^{1}$ University of Economics in Bratislava, Faculty of Business Management, Department of Business \\ Economy, Dolnozemská cesta1, 85235 Bratislava, Slovak republic \\ ${ }^{2}$ University of Economics in Bratislava, Faculty of Business Management, Department of Business \\ Economy, Dolnozemská cesta1, 85235 Bratislava, Slovak republic
}

\begin{abstract}
For the companies the situation in the industry is important in terms of identification opportunities and threats that occur in the industry. Given the increasing competition should be monitored as concentration develops in the industry in which it operates. This article examines the use of the Herfindahl-Hirschman index and Concentration ratio in selected sectors of the creative industry. The development and degree of concentration in the sector is an essential factor characterizing the level of the competitive environment and its exact definition is based on the system of quantitative characteristics that are part of the analytical materials of the institutions dealing with the enforcement of competition rules in most developed economies.
\end{abstract}

\section{Introduction}

In recent years, the importance of the cultural economy and of the cultural and creative industries has grown. The creative and cultural economy is said to be an important and growing part of the global world because of socio-economic potential, creativity, knowledge and information, job creation, wealth and cultural involvement. The basic condition for the existence of a company is competitiveness. One way to monitor competitiveness in the industry is measuring concentration in industry. The development and degree of concentration in the industry is an essential factor characterizing the level of the competitive environment. The paper focuses on the measurement of concentration in selected sectors of creative industry using the Herfindahl-Hirshman index and concentration ratios.

\section{Creative industry}

Creative industries can be defined as the area of overlap between culture, technology, science, and commerce. They involve the supply of goods and services that contain a substantial element of artistic and intellectual activities associated with a vital role in social

\footnotetext{
${ }^{*}$ Corresponding author: maria.kozakova@euba.sk
} 
and human development. [13] Although we can find different definitions of the creative industries, in most research that sector has been investigated mainly based on specific characteristics [9].

Creative enterprises are particularly important for the economy as they have an impact on building the economic potential of countries, cities and regions. [1]. The creative industries involve the concretization of an image, through whatever medium for some form of economic return [2]. Due to creative industries major impact on the development of the economy and the society, cultural organizations and creative companies, which generate creativity, should attract more interest and support from state institutions [9]. Especially at the early stage of its development, the creative sector needs to be supported by the state. [11] According to Campell [8] there is much high-level assertion of creative industries role both for social cohesion and economic growth. The importance of creative industries is that the creative industries are a key contributor to innovation economies [7]. Ideas, processes, products and talent that are developed by the creative industries drive productivity in and outside these industries [14]. Games [6] states, that combining small and medium-sized enterprises (SMEs) and creative industries may offer an advantage of the economic development of the emerging economy. SMEs simply want to find a way to survive because they do not have alternatives, but this may not be the case in SMEs in the creative industries as they pursue business for innovation rather than merely survival. Creative industry is also important job creator. Combined with the expansion of the media, entertainment and design industries, the appeal of creative work in recent years has increased the number of people who do work and want to work in the creative industry [5]. Cnossen [5] also states that workers and entrepreneurs in the creative industry are differently motivated than workers in other sectors, because they are fuelled by "psychic rewards".

UNCTAD [15] makes a distinction between "upstream activities" (traditional cultural activities such as performing arts or visual arts) and "downstream activities" (much closer to the market, such as advertising, publishing or media-related activities) and argues that the second group derives its commercial value from low reproduction costs and easy transfer to other economic domains. The UNCTAD classification of creative industries is divided into nine subgroups, as presented in figure 1.[15]

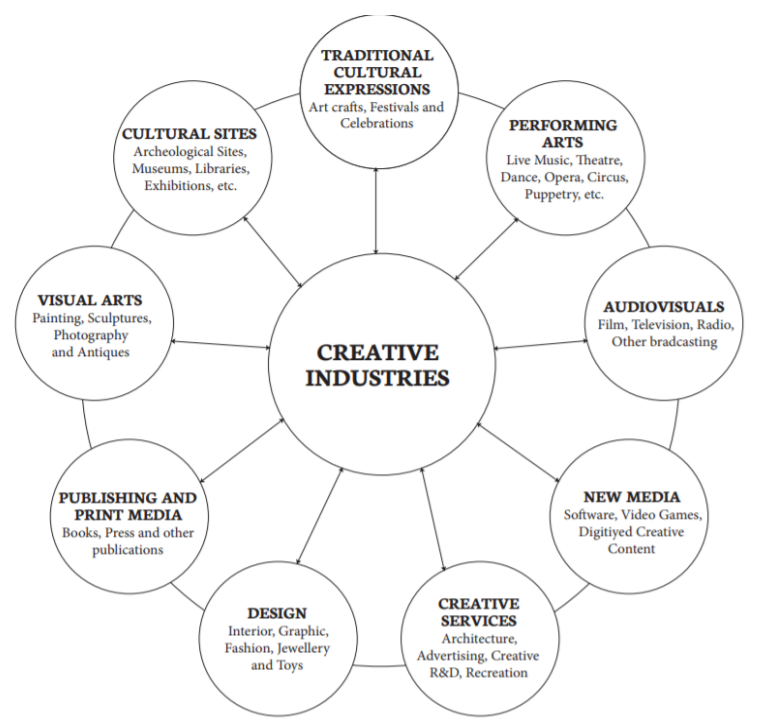

Fig. 1. Classification of creative industries 


\subsection{Measuring market concentration in industry}

Monitoring the situation in the sector is extremely important for the company in identifying opportunities and threats that exist in the industry. One of the possibilities is to monitor competitors, whether existing or potential, which could affect the industry but also the attractiveness of the industry itself. If the industry is attractive, prosperous, it is likely to also attract new competitors to enter it, which may affect the industry's competitive environment. Concentration by industry is a function of the number of companies operating and their respective market shares in total sales. According to Kavčáková [16] measuring of the market concentration of a given sector is particularly important because it is closely linked to the competitiveness of the companies in that sector.

The concentration ratio (CR) and Herfindahl-Hirschman index (HHI) have become the most popular indicators for measuring market concentration in empirical research due to the simplicity of their calculation. However, the latter indicator requires the market shares (or sales volumes) of all the companies in the market to be known. [4] The concentration ratio $\mathrm{CR}_{\mathrm{m}}$ can be defined as the combined market share of the $\mathrm{m}$ largest firms within the market. The most common concentration ratios are the $\mathrm{CR}_{4}$ and the $\mathrm{CR}_{8}$, which means the market share of the four and the eight largest firms. The Hirfindahl-Hirschman Index (HHI) is a standard index used in analysing the degree of market concentration of a particular industry in a particular geographic market. It has been employed as a proxy for the level of competition in a market, measuring how close the market is either to a monopoly or to a perfect competition scenario. [3]

\section{Methodology and data}

Within the creative industry, we focused on measuring concentration in 3 sectors: Book publishing (NACE 58110), Publishing of newspapers (NACE 58130) and Publishing of journals and periodicals (NACE 58140). The results were processed on the available information on revenues of individual entities for 2017 and 2018. The data was obtained from database FinStat.

First, it was necessary to calculate the market share of each company in the industry, because the methods we use to evaluate the degree of concentration in the industry are based on the market share. Market share constitutes the share of firm in a given market or industry:

$$
\mathrm{r}_{\mathrm{k}}=\mathrm{q}_{\mathrm{k}} / \mathrm{Q}
$$

where:

$\mathrm{q}_{\mathrm{k}}-\mathrm{q}_{\mathrm{k}}$ indicates the volume of the $\mathrm{i}$-th firm in the industry,

$\mathrm{Q}-$ represent the total volume of industry output.

Concentration Ratio $\left(\mathrm{CR}_{\mathrm{m}}\right)$ is the most widely used index due to its simplicity and low requirements for input. It is sum of shares of $n$ biggest companies on a market. [17]

$$
C R_{m}=\sum_{i=1}^{m} s_{i} \quad m \epsilon<1 ; n>
$$

where:

si - the market share of the i-th enterprise,

$\mathrm{m}-$ the number of enterprises analysed. 
Value of the index ranges from 0 to 1 . The higher the value is the higher is rate of market concentration on given market. To consider the degree of concentration according to the four most powerful companies in the industry (CR4) by the Federal Trade Commission in the USA the industry is [18]:

- unconcentrated - if the 4 strongest companies produce less than $25 \%$ of industry output $\left(\mathrm{CR}_{4}<0,25\right)$,

- moderately concentrated - if the four most powerful companies produce at least $25 \%$ and less han $50 \%$ of industry output $\left(0,25 \leq \mathrm{CR}_{4}<0,5\right)$,

- concentrated - if the 4 strongest companies in the industry producing at least $50 \%$ of industry output (CR4 $\geq 0,50)$.

In our contribution we also calculate marginal concentration ratio. This latter measure is defined as the difference between $\mathrm{CR}_{4}$ nad the eight-firm concentration ratio $\mathrm{CR}_{8}$.

Herfindahlov-Hirschmanov index (HHI) as a tool used for the measurement of the market concentration is calculated as the sum of the squares of the market shares of the individual companies HHI is used in the two forms [19]:

- Value of HHI is left as a decimal,

- $\quad$ Value of HHI is multiplied by 10000.

$$
H H I=\sum_{i=1}^{n}\left(\frac{x_{i}}{\sum_{i=1}^{n} x_{i}}\right)^{2}
$$

where:

$\mathrm{n}$ - marks number of comapnies on a market,

$x i-$ is share of $i$-th company on a market.

Value range of the index is from 0 to 10000 . If there is only one company in the industry, the index reaches the highest value of 10000 . Classification of the degree of concentration in the industry by the calculated index value, which indicates the Federal Trade Commission (FTC) in USA is [16]:

- $\quad$ unconcentrated - $(\mathrm{HHI}<1000)$

- $\quad$ moderately concentrated - (HHI od 1000 - 1800)

- $\quad$ concentrated $-(\mathrm{HHI}>1800)$.

\section{Results}

We analyze concentration in selected sectors on the basis of revenue. On the basis of this data the share of individual companies in sector was calculated. Concentration rates for $\mathrm{m}$ of the strongest firms in the industry are displayed in figures.

For year 2017, concentration ratios for sector Book publishing indicate concentrated market. Concentration ratio for the largest company in 2017 is $43,7 \%$, the strongest company has a market share of $43,7 \%$. In 2018 is concentration ratio $41,78 \%$. The combined market share of the four biggest companies is 59,76\% in 2017 and $61,81 \%$ in 2018. According to Federal Trade Commission in the USA the industry is concentrated, because the 4 strongest companies in the industry producing more than $50 \%$ of industry 
output (CR4 $\geq 0,50)$. Marginal concentration ratio indicates that the difference between CR4 and the eight-firm concentration ratio CR8 is $11,09 \%$ in 2017 and 8,98\% in 2018.

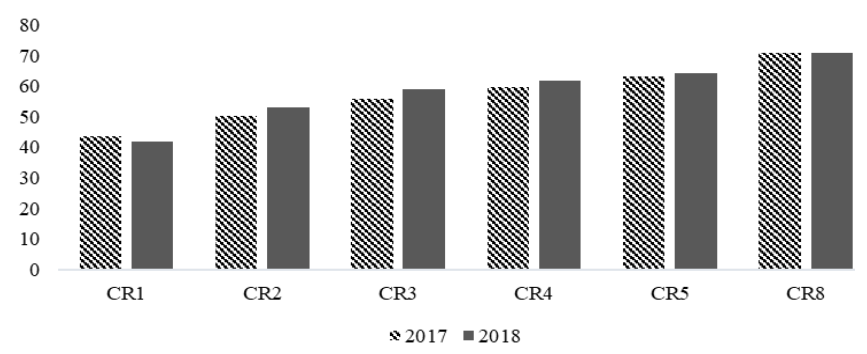

Fig. 2. Concentration ratio - Book publishing

Results of concentrations ratios in second sector - Publishing of newspapers are similar to first industry. Concentration ratio for the 4 largest companies in 2017 is $79,07 \%$ and in $201880,24 \%$. We can conclude, that this industry is concentrated, because 4 strongest companies in the industry producing more than $50 \%$ of industry output (CR4 $\geq 0,50)$.

Marginal concentration ratio indicates that the difference between CR4 and the eight-firm concentration ratio CR8 is 9,54\% in 2017 and 10,14 \% in 2018.

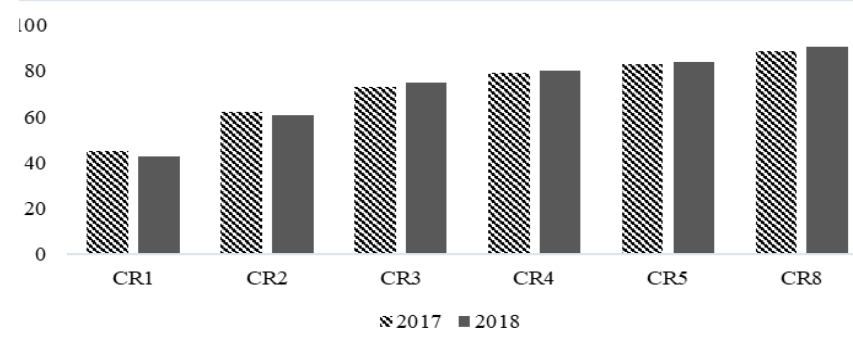

Fig. 3. Concentration ratio - Publishing of newspapers

Results of concentrations ratios in third sector - Publishing of journals and periodicals are also similar to first industry. Concentration ratio for the 4 largest companies in 2017 is $61,08 \%$ and in $201859,96 \%$. We can conclude, that this industry is concentrated, because 4 strongest companies in the industry producing more than $50 \%$ of industry output (CR4 $\geq$ 0,50). From all selected sectors is the highly concentrated sector- Publishing of newspapers. Marginal concentration ratio indicates that the difference between CR4 and the eight-firm concentration ratio CR8 is $11,98 \%$ in 2017 and $11,12 \%$ in 2018 .

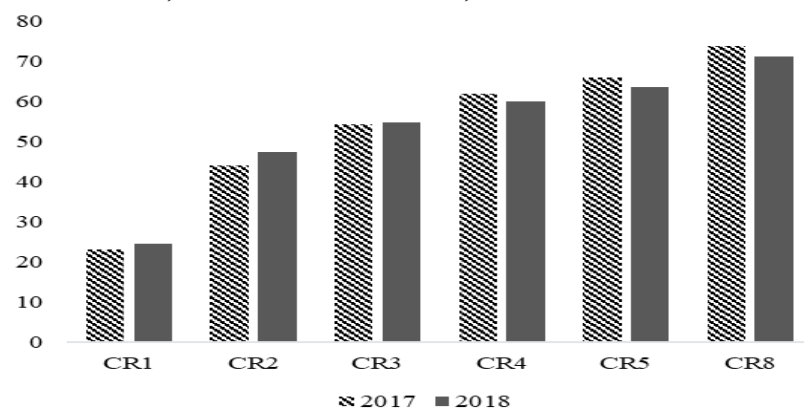

Fig. 4. Concentration ratio - Publishing of journals and periodicals 
An analysis of computed results of the Herfindahl-Hirschman Index, which is based on the classification of the degree of concentration in the sector, shows that all of the calculated values of HHI are greater than 1800. Only HHI for sector Publishing of newspapers is from interval $(1000<\mathrm{HHI}<1800)$. This sector can be classified as moderately concentrated. The results of HHI are displeyad in figure 5.

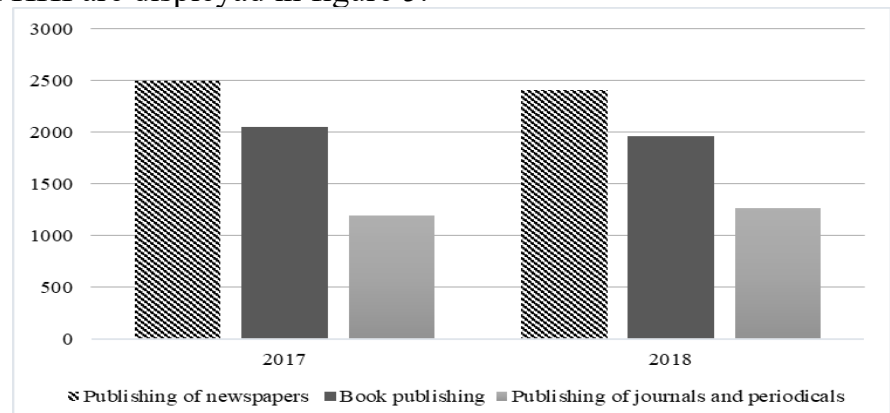

Fig. 5. Herfindahl-Hirshman index

We used Lorenz curve for illustration the situation in selected sectors. The Lorenz Curve is a tool used to represent income distributions as proposed by and it tells us which proportion of total income is in the hands of a given percentage of population.

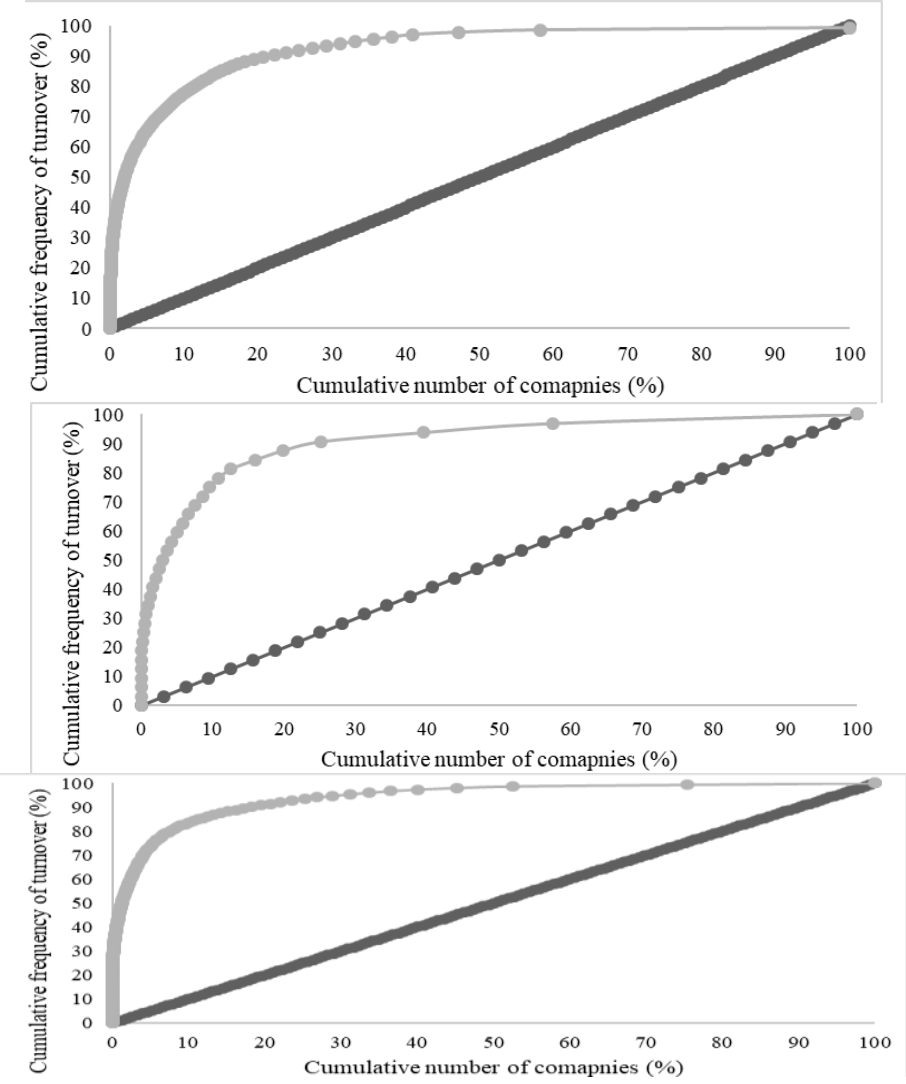

Fig. 6. Lorenz curve - Book Publishing, Publishing of newspapers and Publishing of journals and periodicals 


\section{Conclusions}

Over the last years, the importance of the so-called cultural economy and of the cultural and creative industries has greatly increased. Today, cultural and creative industries are driving factors for economic growth and according to global demand, also stimulated by the new economy. [12] The basic condition for the existence of a company is competitiveness. One way to monitor competitiveness in the industry is measuring concentration in industry.

Market concentration analysis of the sectors - Book publishing, Publishing of newspaper and Publishing of journals and periodicals, based on indicators such as HHI and concentration ratio, that the selected sectors of creative industry are concentrated . The concentration rate for the sector Book Publishing confirms that the 4 strongest companies control from $59-62 \%$ of the industry's total sales (CR4 $=059-0.62)$, in the sector Publishing of newspapers 4 strongest companies control from $79-81 \%$ of the industry's total sales $(\mathrm{CR} 4=0,79-0,81)$ and in sector Publishing of journals and periodicals 4 strongest companies control from $60-61 \%$ of the industry's total sales (CR4 $=0,6-0,61)$. In drawing the conclusions, we use d the US FTC methodology, which states that the industry is highly concentrated if the share of the 4 largest companies in the industry is more than $50 \%$. The results are also confirmed by the HHI. HHI for each sector was analyzed for year 2017 and 2018. According to the used classification of HHI, the selected sectors are concentrated. Only sector -Publishing of newspaper can be classified as moderately concentrated. Lorenz curve graphically displays the unequal distribution of the turnover on the selcted sectors of creative industry.

This paper is an outcome of the research project VEGA n. 1/0340/19 "The Entrepreneurial Dimension of Creative industries in the Context of Innovation and Smart Growth" in the range of 50\% and Internal Grant I-20-101-00 Research of creative industry enterprises with regard to their life cycle in the Slovak Republic in the range of $50 \%$ ).

\section{References}

1. M. Ratalewska, The Role of Entrepreneurship and Business Consulting in Companies in Creative Industries. Management Issues - Problemy Zarż̀dzania, 16, 1 (2018)

2. J. Cerneviciute, R. Strazdas, Teamwork management in creative industries: Factors influencing productivity. Enterpreunership and Sustainbility Issues, 6, 503 - 516 (2018)

3. T. O. Kvålseth, Relationship between concentration ratio and Herfindahl-Hirschman index: A re-examination based on majorization theory. Heliyon, 4, 1-24 (2018)

4. A. Krivka, On the Concept of Market Concentration, the Minimum HerfindahlHirschman Index, and Its Practical Application. Panoeconomicus, 63, 525-540 (2016)

5. B. Cnossen, E. Loots, A. van Witteloostuijn, Individual motivation among entrepreneurs in the creative and cultural industries: A self-determination perspective. Creativity and Innovation Management, 28, 389 - 402 (2019)

6. D. Games, R. P. Rendi, The effects of knowledge management and risk taking on SME financial performance in creative industries in an emerging market: the mediating effect of innovation outcomes. Journal of Global Entrepreneurship Research, 9, 1-14 (2019) 
7. Y. Wijngaarden, E. Hitters, P.V. Bhansing, 'Innovation is a dirty word': contesting innovation in the creative industries. International Journal of Cultural Policy, 25, 392-405 (2019)

8. P. Campbell, D. O'Brien, M. Taylor, Cultural Engagement and the Economic Performance of the Cultural and Creative Industries: An Occupational Critique. Sociology - The Journal of the British Sociological Association, 53, 347-367 (2019)

9. J. Radomska, P. Wolczek, L. Soloducho-Pelc, S. Silva, The Impact of Trust on the Approach to Management: A Case Study of Creative Industries. Sustainability, 11, 816 (2019)

10. I. Hermanson, M. McKelvey, O. Zaring, The evolution and embeddedness of knowledge-intensive entrepreneurial firms in creative industries: contrasting experienced and non-experienced entrepreneurs in the Swedish fashion industry. European Planning Studies, 26, 2387-2406 (2018)

11. A. Drab-Kurowska, State intervention in the context of creative industries. Management - Poland, 22, 74-84 (2018)

12. N. Boccella, I. Salerno, Creative Economy, Cultural Industries and Local Development. Procedia - Social and Behavioral Sciences, 223, 291-296 (2016)

13. E. Martinaitytè, R. Kregždaite, The factors of creative industries development in nowadays stage. Economics and Sociology, 8, 1 (2015)

14. S. Cunningham, Hidden Innovation: Policy, Industry and the Creative Sector. Queensland: University of Queensland Press (2013)

15. UNCTAD. Creative Economy https://unctad.org/en/docs/ditc20082cer_en.pdf (2008)

report, online at

16. M. Kavčáková, Hodnotenie koncentrácie odvetvia pomocou HerfindahlovhoHirschmanovho indexu a jeho komparácia s ostatnými ukazovatel'mi koncentrácie odvetvia. Finančné trhy, 4, (2018).

17. P. Svoboda. Analysis of market concentration in selected sectors of public procurement. Acta Universitatis Agriculturae et Silviculturae Mendelianae Brunensis, 64, 3 (2016)

18. I. Brezina, J. Pekár, Z. Čičková, Zmeny v koncentrácii slovenského bankového sektora. Finančný manažér. 12, 3 (2012)

19. M. Šindeláŕ, The analysis of market concentration of audit services in the Czech Republic. European Financial Systems 2015. Proceedings of the 12th International Scientific Conference, Brno: Masaryk University, 618-624, (2015) 